\title{
LINEAR MATRIX INEQUALITY BASED SYNTHESIS OF PI CONTROLLERS FOR PMSM WITH UNCERTAIN PARAMETERS
}

\author{
Gustavo G. Koch ${ }^{1}$, Thieli S. Gabbi ${ }^{1}$, Rodrigo P. Vieira ${ }^{1}$, Humberto Pinheiro ${ }^{1}$, Thiago A. Bernardes ${ }^{2}$, \\ Ricardo C. L. F. Oliveira ${ }^{3}$, Vinícius F. Montagner ${ }^{1}$ \\ ${ }^{1}$ Federal University of Santa Maria - UFSM, Santa Maria - RS, Brazil \\ ${ }^{2}$ Federal Institute of Brasília - IFB, Brasília - DF, Brazil \\ ${ }^{3}$ University of Campinas - UNICAMP, Campinas - SP, Brazil \\ e-mail: gustavoguilhermekoch@gmail.com
}

\begin{abstract}
This paper addresses the design of robust PI controllers for permanent magnet synchronous motors in terms of a linear matrix inequality based problem. A polytopic model of the plant is obtained and validated for the motor uncertain parameters belonging to intervals. The design procedure proposed here encompasses: $i$. suitable plant uncertainties inclusion and the use of practical design control constraints; ii. robust PI computation based on linear matrix inequalities with a very fast solution; iii. simulation analyses; and iv. experimental evaluations. The robust PI controller can produce superior speed regulation than a PI controller designed only for the nominal parameters, including better disturbance rejection and $\mathscr{H}_{\infty}$ performance. Experimental results confirm the viability of the proposal, which can be seen as an efficient alternative to trade off performance and robustness for PI controllers in this application.
\end{abstract}

Keywords - Linear Matrix Inequalities, Permanent Magnet Synchronous Motor, Robust Control, Uncertain Parameter.

\section{INTRODUCTION}

Electric motors are used in several areas, as for instance, in industry and transportation, motivating the research on constructive features and on high performance drivers [1][3]. One important category of electric motors includes the permanent magnet synchronous motors (PMSM), which provides high efficiency associated with high power density, being especially useful for applications that require motion control as, for example, industrial robots, railways and wind energy conversion systems [4]-[11]. However, the control of PMSMs is challenging due to the nonlinear behavior and the presence of disturbances and uncertainties affecting the motor [12]. Nonlinear control techniques can be used, aiming to ensure the high performance of PMSM drives. In [13], it is proposed a speed control technique using an adaptive PID controller. The controller consists of three terms intended to compensate the nonlinearities, adjust the gains and ensure the stability of the system. In [14], a nonlinear combined speed control is developed. This control method combines a sliding mode technique with a disturbance observer, aiming to compensate the disturbances and uncertainties of the PMSM. In [15], a predictive scheme for speed control of a PMSM was

Manuscript received 19/12/2017; first revision 03/04/2018; accepted for publication 31/05/2018, by recommendation of Editor Marcello Mezaroba. presented. A comparison with PI controller was carried out to verify dynamic performance. In [16], a speed controller based on the combination of fuzzy and sliding mode control schemes is used, to reduce chattering and to improve robustness to uncertain parameters, with a load torque observer based on linear matrix inequalities (LMIs) [17]. In [18], the PMSM is modeled based on a Takagi-Sugeno fuzzy description. A set of LMIs is solved to get the fuzzy load torque observer gains, and another set of LMIs is solved to get the fuzzy speed regulator gains. In [19], Takagi-Sugeno fuzzy controllers are used with internal model controllers for PMSM speed regulation, with results validated in hardware-in-the-loop.

Although nonlinear techniques are important for the achievement high performance, they are more complex than fixed-gain PI controllers, which are used in regulation of variables in several industry applications, providing suitable performance with a very simple control structure [20]. In [21], PI controllers are used for current control in grid connected converters modelled in $d q$ coordinates. This model is also used in maximum power point tracking in photovoltaic applications, as in [22]. In [23], the gains of a PI are obtained to ensure desired transient responses for a second order closed-loop model in a photovoltaic system. The paper [24] presents some alternatives of PIs for current regulation of induction motors, using synchronous frame and stationary frame PI controllers. In [25], a PI is used for speed control of a PMSM designed only for nominal model parameters. To ensure robustness the design of controllers can also be described in terms of LMIs, as in [26]-[28]. In [29], an $\mathscr{H}_{\infty}$ controller is applied to speed regulation of a PMSM, providing robustness to disturbances, but only for a nominal model of the motor, and only presenting simulation results with ranges of currents that are impracticable. Thus, there is a lack of studies on more detailed designs for PIs, implemented based only on a single pair of fixed control gains, capable of ensuring a good tradeoff between performance and robustness against uncertain parameters in experimental applications to PMSM.

The main contribution of this paper is to provide a systematic procedure to design, off-line, fixed gain PI controllers that ensure: i) robust pole location based on LMIs for a set of uncertainties in the PMSM parameters, ii) robust stability certification based on LMIs for arbitrary time variations on the PMSM parameters and iii) evaluate experimentally the viability of the robust controller. To achieve this, a polytopic model of the PMSM is obtained and validated for given intervals of mechanical parameters. The design parameters in the LMIs are chosen in order to 


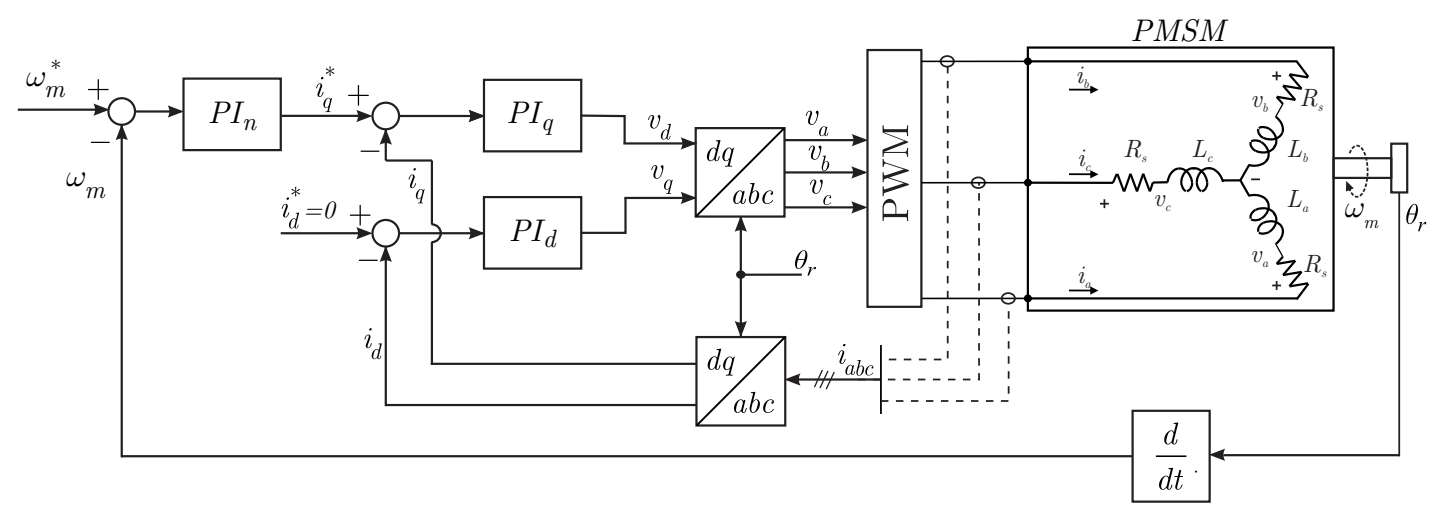

Fig. 1. Block diagram of the PMSM control system.

obtain step reference responses that respect upper bounds of overshoot and settling times suitable for the application. Several simulations of speed reference tracking are given under mechanical uncertain parameters, evaluating also the control signal and the rejection of disturbances, including the computation of an $\mathscr{H}_{\infty}$ guaranteed cost for the closedloop system. The proposed controller can provide better performance than a PI designed only for nominal parameters, with results experimentally confirmed in a commercial PMSM.

\section{DESCRIPTION OF THE PROBLEM}

Consider the control system of an internal PMSM given in Figure 1, where a rotor field oriented strategy is used. The system is composed by one speed control loop and two current control loops. The speed compensator processes the error between the reference $\omega_{m}^{*}$ and the actual speed $\omega_{m}$, to generate the reference of current $i_{q}^{*}$. The control strategy imposes $i_{d}^{*}=0$ to linearize the electromechanical torque. Current sensors provide the phase currents $a b c$, which are converted in synchronous axes $d q$ currents, by the transformation given in [30], based on the measured angular position $\theta_{r}$. The outputs of the controllers $P I_{d}$ and $P I_{q}$ provide the voltages $v_{d}$ and $v_{q}$, which are transformed in $a b c$ voltages and then converted to pulse-width modulation (PWM) signals, to drive the PMSM.

A representation of the PMSM in $d q$ synchronous coordinates is given by [1]

$$
\begin{aligned}
& \frac{d i_{d}}{d t}=-\frac{R_{s}}{L_{d}} i_{d}+\frac{L_{q}}{L_{d}} \omega_{e} i_{q}+\frac{1}{L_{d}} v_{d} \\
& \frac{d i_{q}}{d t}=-\frac{R_{s}}{L_{q}} i_{q}-\frac{L_{d}}{L_{q}} \omega_{e} i_{d}-\frac{\phi_{s r m}}{L_{q}} \omega_{e}+\frac{1}{L_{q}} v_{q}
\end{aligned}
$$

where the subscription $d$ and $q$ indicate the direct and quadrature axes; $i_{d}, i_{q}, v_{d}$ and $v_{q}$ are the currents and voltages in a synchronous reference frame; $L_{d}$ and $L_{q}$ are the stator inductance referred to the synchronous reference frame; $R_{S}$ is the stator resistance; $\phi_{s r m}$ is the magnetic flux of the permanent magnet, and $\omega_{e}$ is the electrical angular speed. Note that the parameters referent to the inductances are different for axes $d$ and $q$, due to the internal magnet machine configuration.

Assuming that the terms depending on $\omega_{e}$ in (1) and (2) are

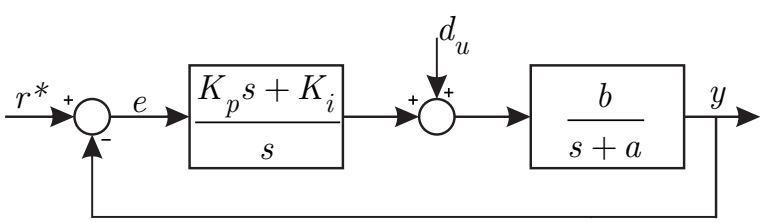

Fig. 2. Control loop with PI and first order plant.

disturbances, one can write the decoupled transfer functions

$$
\begin{gathered}
G_{d}(s)=\frac{I_{d}(s)}{V_{d}(s)}=\frac{\frac{1}{L_{d}}}{s+\frac{R_{s}}{L_{d}}} \\
G_{q}(s)=\frac{I_{q}(s)}{V_{q}(s)}=\frac{\frac{1}{L_{q}}}{s+\frac{R_{s}}{L_{q}}} .
\end{gathered}
$$

The dynamic model for the mechanical behavior is described by [1]

$$
\frac{d w_{m}}{d t}=\frac{1}{J}\left(\tau_{m}-B w_{m}\right)+\delta\left(w_{m}\right)
$$

where $J$ is the moment of inertia of the rotor, $B$ is the viscous friction coefficient, and $\delta\left(w_{m}\right)$ represents a nonlinear term of bounded norm. Additionally, $\tau_{m}$ is the difference between the electromechanical torque, given by $\frac{3}{2} P\left[\left(L_{d}-L_{q}\right) i_{d}+\phi_{s r m}\right] i_{q}$, and the load torque, being $P$ the number of pairs of poles of the motor.

The transfer function from the linear part of (5), considering the mechanical torque as an input and the rotor speed as an output, is written as

$$
G_{n}(s)=\frac{W_{m}(s)}{T_{m}(s)}=\frac{\frac{1}{J}}{s+\frac{B}{J}} .
$$

Note that (3), (4) and (6) are first order systems, which can be described by the general model

$$
G(s)=\frac{b}{s+a} .
$$

The problem to be solved in this paper is to determine the gains $K_{p}$ and $K_{i}$ of a PI controller, given in the feedback loop shown in Figure 2, such that:

(i) the closed-loop poles are located inside the sector depicted in Figure 3, for the plant with uncertain 


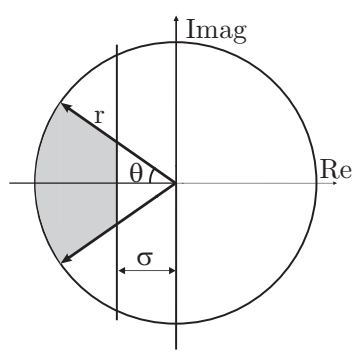

Fig. 3. Sector for the pole location defined by $r, \theta$ and $\sigma$.

parameters belonging to real intervals given by

$$
a \in\left[a_{\min } a_{\max }\right], b \in\left[b_{\min } b_{\max }\right]
$$

(ii) the closed-loop system remains robustly stable for arbitrary time variation of parameters $a$ and $b$ in the intervals (8).

Notice that the location of the closed-loop poles inside the sector given in Figure 3 can be associated with transient responses with settling times and overshoots limited. In addition, the variations of the motor parameters can be provoked by changes of temperature, as well as magnetic saturation, which must be taken into account in the stability analysis [31], [32].

Here, one assumes intervals for $a$ and $b$ centered at nominal values \pm a percentage of tolerance, to encompass the uncertainty on the parameters $L_{d}, L_{q}, R_{s}, B$ and $J$. However, the approach of polytopic representation of the plant shown in the sequence can handle any other real interval for parameters $a$ and $b$, chosen based on the knowledge of the machine by the control designer.

The next section describes the computation of the gains of the PI controllers, based on LMIs, to ensure the desired pole location and the stability against parametric variations.

\section{ROBUST PI CONTROLLER DESIGN}

Assuming the disturbances $d_{u}=0$, the transfer function from reference $r^{*}$ to the output $y$ of the closed-loop system given in Figure 2, can be represented in state-space as

$$
\dot{x}=A(a) x+B_{u}(b) u+B_{r} r^{*}
$$

where

$$
\begin{aligned}
& A(a)=\left[\begin{array}{cc}
0 & 1 \\
0 & -a
\end{array}\right] ; B_{u}(b)=\left[\begin{array}{l}
0 \\
b
\end{array}\right] ; B_{r}=\left[\begin{array}{l}
0 \\
1
\end{array}\right] \\
& x=\left[\begin{array}{c}
\int e \\
e
\end{array}\right]
\end{aligned}
$$

where $\int e \triangleq \int_{0}^{t} e(\tau) d \tau$.

Thus, the PI design can be accomplished in terms of a state feedback design, whose control law is given by

$$
u=K x=\left[\begin{array}{ll}
K_{i} & K_{p}
\end{array}\right]\left[\begin{array}{c}
\int e \\
e
\end{array}\right] .
$$

To compute the control gains $K_{i}$ and $K_{p}$ that ensure the location of the closed-loop poles inside the sector in Figure 3 for $a$ and $b$ assuming any value in (8), a polytopic model for
(9) can be obtained. This model is given by

$$
\dot{x}=A_{p}(\alpha) x+B_{p}(\alpha) u+B_{r} r^{*}
$$

where the matrices are written as

$$
\begin{aligned}
& \left(A_{p}, B_{p}\right)(\alpha)=\sum_{i=1}^{4} \alpha_{i}\left(A_{p}, B_{p}\right)_{i} ; \sum_{i=1}^{4} \alpha_{i}=1 ; \alpha_{i} \geq 0 \\
& i=1, \ldots, 4
\end{aligned}
$$

The matrices

$$
\begin{aligned}
& \left(A_{p}, B_{p}\right)_{1}=\left(A\left(a_{\min }\right), B_{u}\left(b_{\min }\right)\right) \\
& \left(A_{p}, B_{p}\right)_{2}=\left(A\left(a_{\min }\right), B_{u}\left(b_{\max }\right)\right) \\
& \left(A_{p}, B_{p}\right)_{3}=\left(A\left(a_{\max }\right), B_{u}\left(b_{\min }\right)\right) \\
& \left(A_{p}, B_{p}\right)_{4}=\left(A\left(a_{\max }\right), B_{u}\left(b_{\max }\right)\right)
\end{aligned}
$$

in (13) are known as the vertices of this polytopic model.

A solution for the problem described in Section II can be obtained using the LMI conditions given in Theorem 1 .

Theorem 1. Given $r>0,0<\theta<\frac{\pi}{2}$ and $\sigma>0$, and matrices $A_{p i}$ and $B_{p i}, i=1, \ldots, 4$, if there exist a symmetric positive definite matrix $X \in \mathbb{R}^{2 \times 2}$ and a matrix $Z \in \mathbb{R}^{1 \times 2}$ such that [33]

$$
\begin{gathered}
A_{p i} X+X A_{i}{ }^{\prime}+B_{p i} Z+Z^{\prime} B_{p i}{ }^{\prime}+2 \sigma X<0 \\
{\left[\begin{array}{cc}
-r X & \star \\
A_{p i} X+B_{p i} Z & -r X
\end{array}\right]<0}
\end{gathered}
$$

$$
\begin{aligned}
& {\left[\begin{array}{cc}
M_{11} & M_{12} \\
\star & M_{22}
\end{array}\right]<0} \\
& M_{11}=\sin (\theta)\left(A_{p i} X+X A_{p i}{ }^{\prime}+B_{p i} Z+Z^{\prime} B_{p i}{ }^{\prime}\right) \\
& M_{12}=\cos (\theta)\left(A_{p i} X-X A_{p i}{ }^{\prime}+B_{p i} Z-Z^{\prime} B_{p i}{ }^{\prime}\right) \\
& M_{22}=M_{11}
\end{aligned}
$$

are feasible, for $i=1, \ldots, 4$, then

$$
K=Z X^{-1}=\left[K_{i} K_{p}\right]
$$

provides the gains of a PI controller which ensures: (i) the location of the closed-loop poles in the sector given in Figure 3 and (ii) the stability of the closed-loop system under arbitrary variations of $a$ and $b$ in (8).

Two main ideas can be used to prove the conditions of Theorem 1. The result from [33] is used guarantee the pole location and the result from [17] is employed to assure the quadratic stability of the closed-loop system, certifying the robust stability for arbitrarily fast variations of the timevarying parameters $a$ and $b$.

Theorem 1 is expressed as a feasibility problem to allow the control designer specify values for $r, \theta$ and $\sigma$, to establish a region for robust pole location that can meet constraints in terms of settling time, overshoot and control limit.

For an investigation of the use of Theorem 1, consider the control loop in Figure 2 with the transfer function of the plant given by (6).

The symbol $\star$ represents symmetric blocks in the LMIs. 


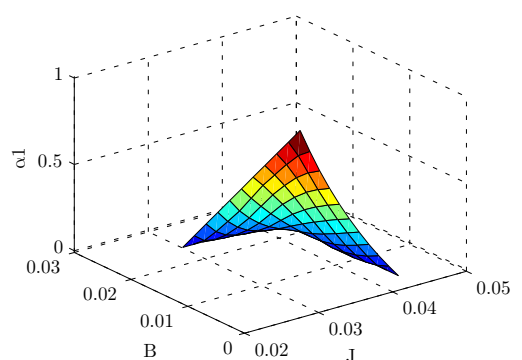

(a)

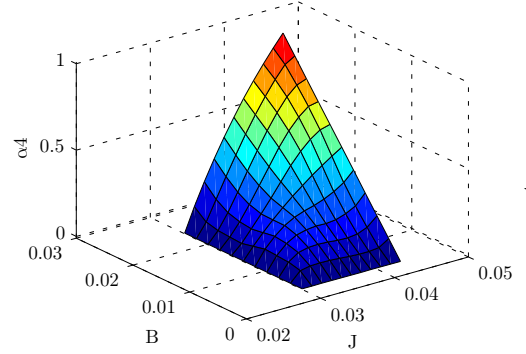

(d)

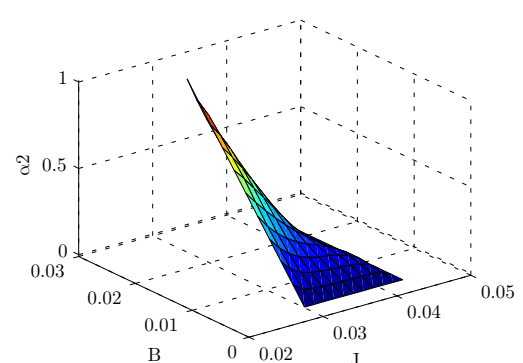

(b)

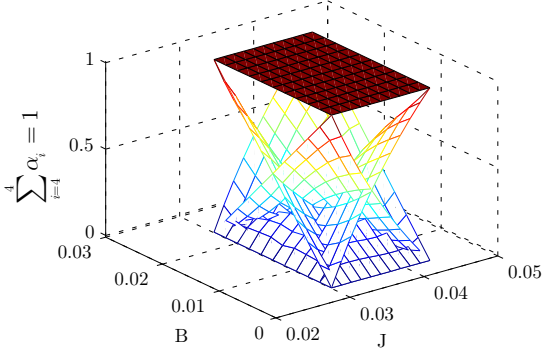

(e)

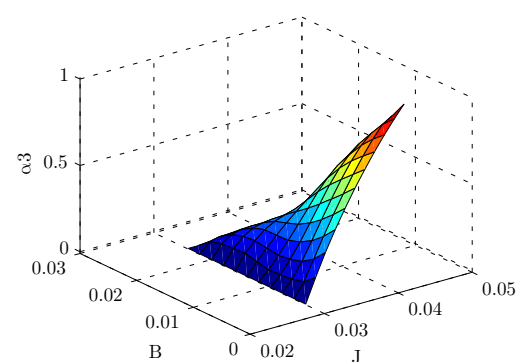

(c)

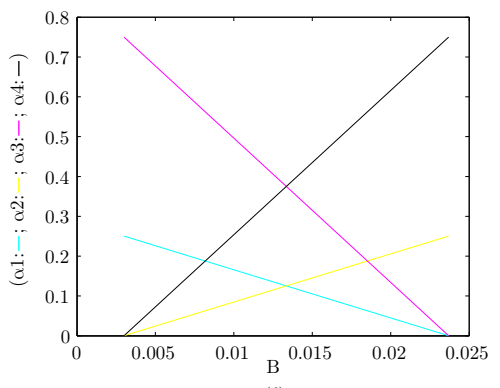

(f)

Fig. 4. Validation of the polytopic model: (a) to (d) parameters $\alpha_{i} \geq 0, i=1, \ldots, 4$ of the polytopic model, for $J$ and B respecting (19). (e) Sum of $\alpha_{i}$ equal to 1 , confirming convexity. (f) Values of $\alpha_{i}$ for the case where $J$ is fixed at 0.03877 .

To obtain the polytopic model, consider

$$
\begin{aligned}
& a_{\min }=0.2502 ; a_{\max }=0.7506 ; \\
& b_{\min }=23.2138 ; b_{\max }=28.3725 .
\end{aligned}
$$

The limits of the parameter $a$ were obtained by the expression $(B / J) \pm 50 \%$, with nominal values

$$
J=0.03877 \mathrm{kgm}^{2} ; B=0.0194 \mathrm{Nms}
$$

and the limits of the parameter $b$ were obtained by the expression $(1 / J) \pm 10 \%$.

Writing the four vertices of the polytopic model as in (14), Figure 4 shows that, for each pair $(J, B)$ respecting the limits from (19), there exists a set of parameters $\alpha_{i} \geq 0, i=1, \ldots, 4$, $\sum_{i=1}^{4} \alpha_{i}=1$ which allows to represent the matrices in (10) by (13)-(14). Thus, the polytopic model includes suitably the plant for all the set of uncertain parameters and the design of robust controllers using the conditions of Theorem 1 can be addressed based only on the vertices $\left(A_{p}, B_{p}\right)_{i}, i=1, \ldots, 4$ of the polytope, due to the convexity property [17].

To help the control designer in the choice of $\sigma, r$, and $\theta$, in the use of Theorem 1, an investigation is carried out now in the space $\sigma, r$, with $\theta$ fixed at $\pi / 10$ to ensure small overshoots in the transient responses. The results are depicted in Figure 5(a) and Figure 5(b). These figures show, respectively, the settling times and the overshoots of the responses of the closed-loop system in Figure 2 to a unit step reference $\left(d_{u}\right.$ is kept equal to zero).

This investigation indicated that for the sets $r \in[18.525 .5]$ and $\sigma \in[3.55]$, Theorem 1 can provide robust PI controllers with overshoots lower than $15 \%$ and settling times lower than $1 \mathrm{~s}$ (for the criterium of $2 \%$ of steady state error).

For a more detailed interpretation of Figure 5(a), notice

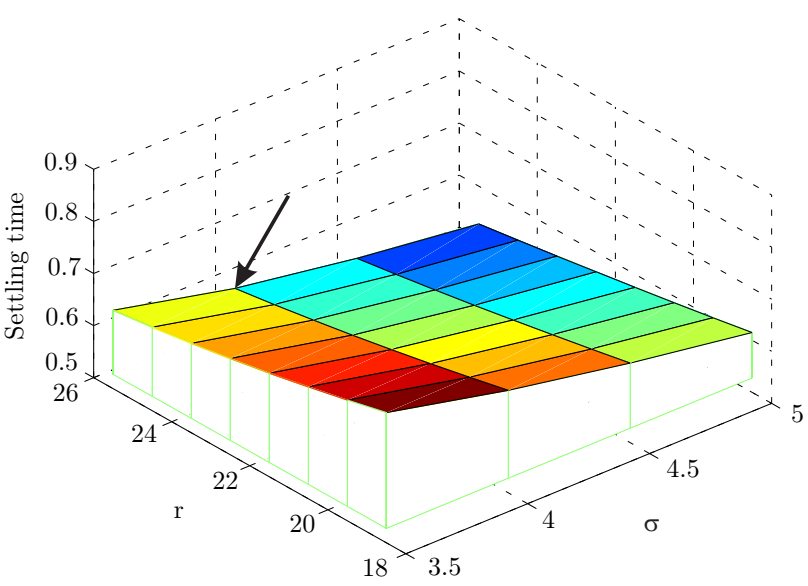

(a)

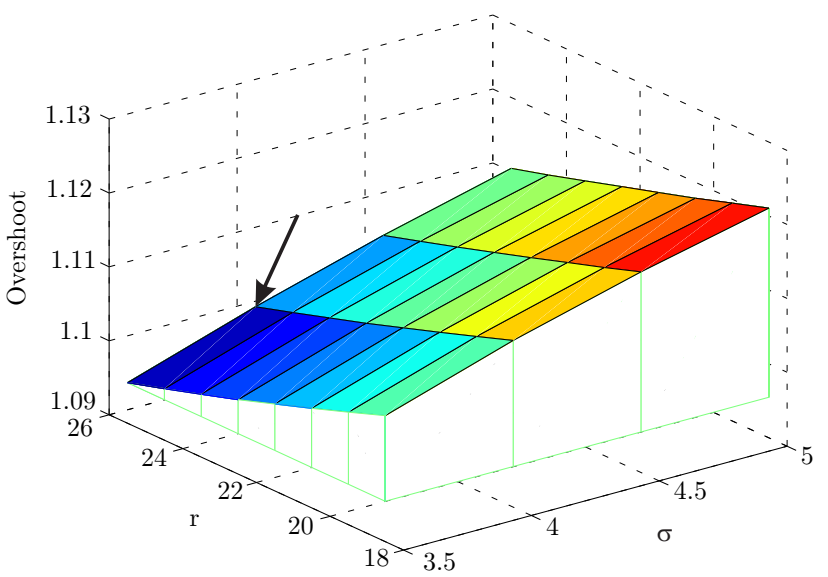

(b)

Fig. 5. Upper bounds for (a) settling times and (b) overshoots, based on Theorem 1, for $r \in[18.525 .5]$ and $\sigma \in[3.55]$, with $\theta$ fixed at $\pi / 10$. 
that the arrow points to the position corresponding to $r=$ 25.5, $\sigma=4(\theta=\pi / 10)$, for which Theorem 1 provides a robust PI that ensures a settling time of 0.5963 seconds. This value is actually the maximum settling time obtained from the simulations of the closed-loop system in Figure 2 with this robust PI and with unit step reference, for a fine grid in parameters $a$ and $b$ respecting (19). The same idea is valid for the arrow in Figure 5(b), which indicates that the robust PI ensures maximum overshoot of $10 \%$ in this case. Notice that lower settling times could be achieved, at the price of higher overshoots.

The next section shows a procedure to get a robust PI to achieve performance in terms of reference tracking and how a controller designed by Theorem 1 can be superior to PI designed only for a nominal model.

\section{SIMULATION AND EXPERIMENTAL RESULTS}

In this section, a robust PI controller is validated by simulation and experimental results. To have a comparison, a PI designed only for the nominal parameters of the plant (referred from now on as conventional PI) is tested under the same conditions of the robust controller.

The following procedure is proposed to obtain robust PIs suitable for experimental tests:

i. provide the maximum and minimum values of the parameters $a$ and $b$ of the plant model, the maximum allowed settling time $\left(t s_{\max }\right)$, overshoot $\left(o v_{\max }\right)$, and control signal amplitude $\left(u_{\max }\right)$ for the responses to a unit step reference;

ii. choose $r, \theta$ and $\sigma$, and solve the LMIs in Theorem 1 to obtain the gains of a robust PI;

iii. verify if the closed-loop system in Figure 2 satisfies the limits $t s_{\max }, o v_{\max }$ and $u_{\max }$, by numerical simulations, for a grid on the parameters $a$ and $b$;

iv. evaluate experimentally the robust PI controller. If $t s_{\max }$, $o v_{\max }$ and $u_{\text {max }}$ are satisfied, stop; otherwise, return to step ii.

For this example, the limits for $a$ and $b$ are given by (19) and the limits for step reference responses were chosen as

$$
\mathrm{ts}_{\max }=0.6 ; \mathrm{ov}_{\max }=1.11 ; u_{\max }=1 .
$$

After a few tests in the sets of $r$ and $\sigma$ given in Section III, one has that the parameters $\sigma=4, r=25.5$ and $\theta=\pi / 10$, for the LMIs in Theorem 1, provided the robust PI controller

$$
G_{P I n}^{r o b}(s)=\frac{0.9247 s+3.657}{s}
$$

achieving the design specifications from (21).

To deal with robust controllers for systems that admit a polytopic model, LMIs are a very efficient alternative. For instance, to compute the speed loop controller (22), a problem of 5 variables and 40 lines of linear inequalities is solved very fast, in an off-line procedure, thus justifying this approach by the high computational efficiency. ${ }^{1}$

The closed-loop poles with the controller (22) belong to the sector chosen for pole location, as confirmed by Figure 6 .

\footnotetext{
${ }^{1}$ Using a notebook with a Core i7 processor and with 8GB of RAM, the LMIs in Theorem 1 were solved in 0.14 seconds.
}

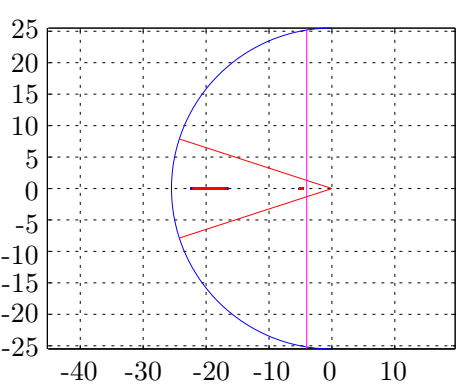

Fig. 6. Closed-loop poles (in red) for the pole location obtained with $\sigma=4, r=25.5$ and $\theta=\pi / 10$.

The matrix

$$
X=\left[\begin{array}{cc}
0.0048 & -0.0229 \\
-0.0229 & 0.1410
\end{array}\right]
$$

is associated with the quadratic Lyapunov function $v(x)=x^{\prime} X x$ obtained by the solution of Theorem 1 , which certifies the stability of the closed-loop system for any arbitrary parameter variation satisfying the limits in (19).

For comparison, a conventional PI controller is designed in the frequency domain, to ensure to the system of Figure 2 a second order response with cutoff frequency defined as two times the natural frequency of the nominal plant, and with damping factor equal to 0.95 , the same used for the robust PI controller. The conventional PI controller obtained is given by

$$
G_{P I n}^{c o n v}(s)=\frac{0.429 s+1.4338}{s} .
$$

For the design of the robust PIs for the current loops, the following limits were used:

$$
\frac{R_{s}}{L_{d}} \pm 50 \%, \frac{R_{s}}{L_{q}} \pm 50 \%, \frac{1}{L_{d}} \pm 10 \%, \frac{1}{L_{q}} \pm 10 \%
$$

where $R_{s}, L_{d}$ and $L_{q}$ are given in Table I.

TABLE I

PMSM Parameters

\begin{tabular}{ll}
\hline \hline Parameter & Value \\
\hline \hline Rated Power & $11 \mathrm{~kW}$ \\
Rated Current & $19.2 \mathrm{~A}$ \\
Rated Torque & $58.4 \mathrm{Nm}$ \\
Poles (P) & 6 \\
Stator Resistance $\left(R_{S}\right)$ & $0.5 \Omega$ \\
Inductance of d-axis $\left(L_{d}\right)$ & $20.1 \mathrm{mH}$ \\
Inductance of q-axis $\left(L_{q}\right)$ & $40.9 \mathrm{mH}$ \\
Rotor Inertia $(J)$ & $0.03877 \mathrm{kgm}{ }^{2}$ \\
Friction Coefficient $(B)$ & $0.0194 \mathrm{Nms}$ \\
PM flux linkage & $0.5126 \mathrm{~V} / \mathrm{rad} / \mathrm{s}$ \\
\hline
\end{tabular}

The limits for step reference responses were chosen as

$$
\mathrm{ts}_{\max }=0.1 ; \mathrm{ov}_{\max }=1.03 ; u_{\max }=1 \text {. }
$$

Following the same procedure that provided the controller $P I_{n}$, Theorem 1 , with $\sigma=20, r=500$ and $\theta=\pi / 10$, provides the following the robust PI for the direct loop:

$$
\mathrm{G}_{\mathrm{PI}_{\mathrm{d}}}(\mathrm{s})=\frac{7.657 s+202.6}{s}
$$




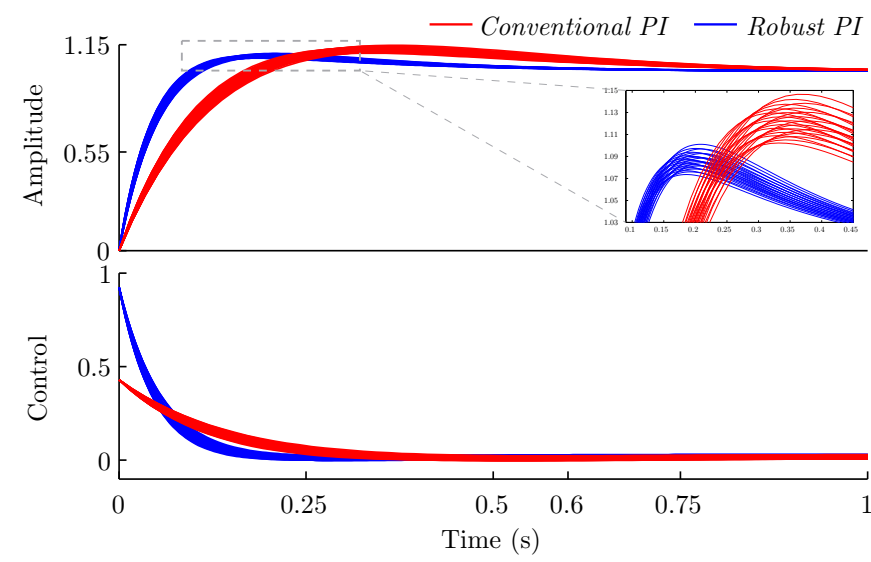

Fig. 7. Responses to a unit step reference showing the overshoots, settling times, and control signals.

In the same way, Theorem 1 , with $\sigma=15, r=500$ and $\theta=\pi / 10$ provides the following the robust PI for the quadrature loop:

$$
\mathrm{G}_{\mathrm{PI}_{q}}(\mathrm{~s})=\frac{15.5 s+300.4}{s} .
$$

These PIs for the current loops are used to test both robust and conventional PIs for the speed loop in the experimental results in the sequence.

Figure 7 shows the responses to a unit step reference of speed for the system in Figure 2, with the robust PI (22) and with the conventional PI (24), for a grid on the plant parameters respecting (19), and the corresponding control signals. Note that the specifications in (21) are achieved and that the robust controller provides better dynamic responses.

Figure 8 confirms the better performance with the robust PI controller for a variation on time on parameters $a$ and $b$.

Figure 9 shows the rejection of unit step disturbances, for the system in Figure 2 with the robust PI controller (22) and the conventional PI (24). Better rejection of disturbances is provided by the robust controller.

For a more detailed analysis, now consider the nonlinear
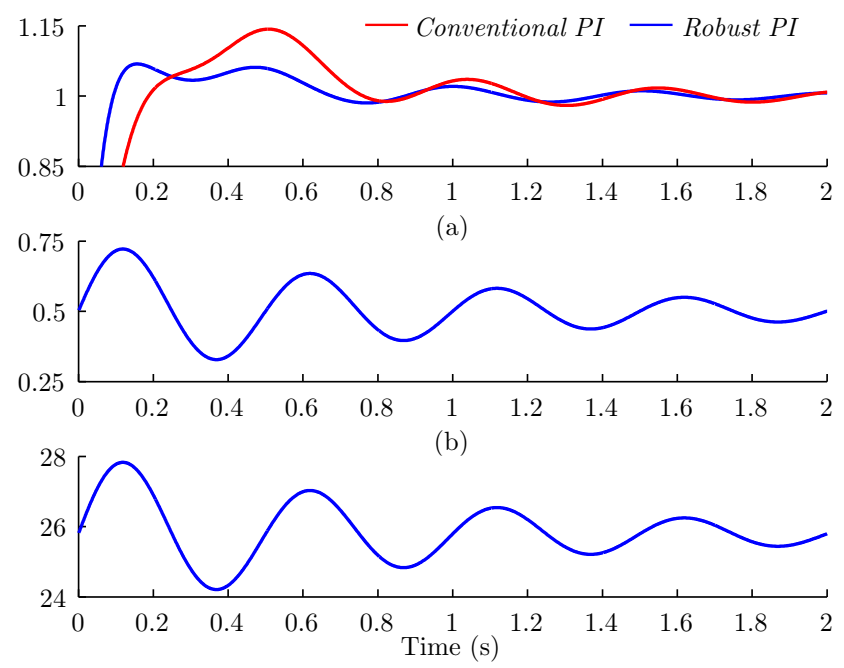

(c)

Fig. 8. (a) Responses to a unit step reference for the robust PI and conventional PI under parameter variations. (b) Variation of parameter $a$. (c) Variation of parameter $b$.

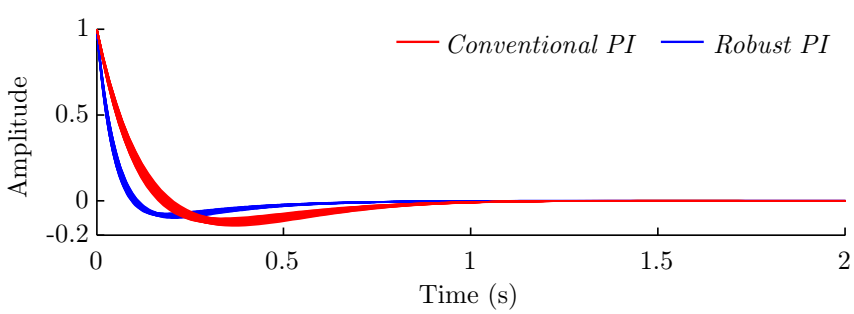

Fig. 9. Responses to a unit step disturbance $d_{u}$ on the control signal, for the robust PI and the conventional PI controllers.

term in (5) represented by a norm bounded disturbance $d_{u}$. Then, the closed-loop system, given in Figure 2, can be described in the state space as

$$
\begin{gathered}
{\left[\begin{array}{l}
x_{1} \\
x_{2}
\end{array}\right]=\left[\begin{array}{cc}
0 & 1 \\
-\left(b K_{i}\right) & -\left(a+b K_{p}\right)
\end{array}\right]\left[\begin{array}{l}
x_{1} \\
x_{2}
\end{array}\right]+\left[\begin{array}{l}
0 \\
1
\end{array}\right] d_{u}} \\
y=\left[\begin{array}{ll}
0 & b
\end{array}\right]\left[\begin{array}{l}
x_{1} \\
x_{2}
\end{array}\right]
\end{gathered}
$$

Given the gains $K_{p}$ and $K_{i}$ and considering $a$ and $b$ with limits in (19), the system (27) and (28) can be represented in a polytopic form as

$$
\begin{gathered}
\dot{x}=A_{d}(\alpha) x+B_{d}(\alpha) d_{u} \\
y=C_{d}(\alpha) x
\end{gathered}
$$

with

$$
\begin{aligned}
& \left(A_{d}, B_{d}, C_{d}\right)(\alpha)=\sum_{i=1}^{4} \alpha_{i}\left(A_{d}, B_{d}, C_{d}\right)_{i} \\
& \sum_{i=1}^{4} \alpha_{i}=1 ; \alpha_{i} \geq 0 ; i=1, \ldots, 4 .
\end{aligned}
$$

The four vertices from (31) are obtained by the evaluation of the respective matrices in (27) and (28) for all the combinations of maximum and minimum values of $a$ and $b$.

From the condition of $\mathscr{H}_{\infty}$ guaranteed cost computation based on quadratic stability [17], one has that, if there exists a symmetric positive definite matrix $X \in \mathbb{R}^{2 \times 2}$ such that

$$
\begin{aligned}
& \eta^{*}=\min \eta \\
& \text { s.t. } \\
& {\left[\begin{array}{ccc}
A_{d i} X+X A_{d i}{ }^{\prime} & B_{d i} & C_{d i}{ }^{\prime} \\
\star & -I & 0 \\
\star & \star & -\eta I
\end{array}\right]<0}
\end{aligned}
$$

has a solution for $i=1, \ldots, 4$, then $\gamma=\sqrt{\eta^{*}}$ is an $\mathscr{H}_{\infty}$ guaranteed cost for the system (29)-(30) [17].

The solution of (32) for the robust PI controller (22) provides $\gamma$ equals to $1.0517 \mathrm{~dB}$. For the conventional PI controller (24), one has $\gamma$ equals to $5.1469 \mathrm{~dB}$, indicating again a better performance with the robust PI controller when concerning disturbance rejection. One can notice by the frequency domain analysis in Figure 10 that the robust PI controller yields disturbance attenuations in practically the entire range of frequencies. This figure also shows a better overall performance of the robust PI controller when compared to the conventional PI, with also a lower upper bound for the magnitude diagram (lower $\mathscr{H}_{\infty}$ guaranteed cost).

A simulation closer to the practical implementation is given 


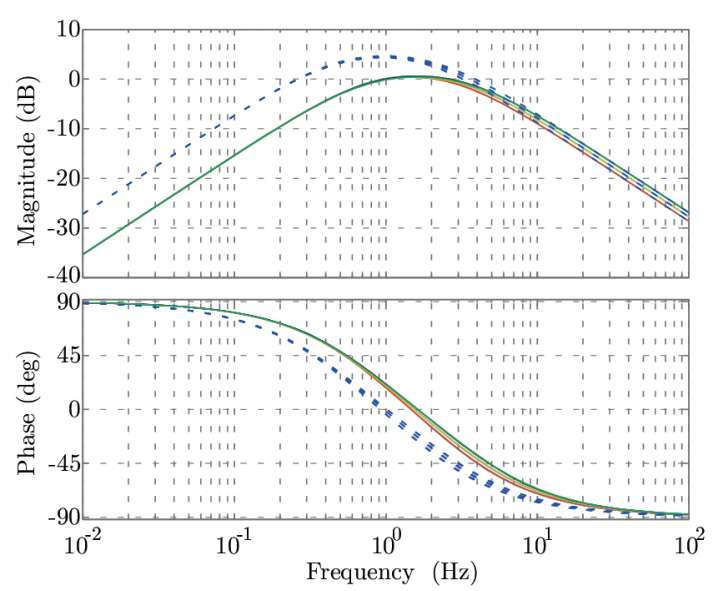

Fig. 10. Frequency response of the system (27), (28), for parameters $a$ and $b$ with limits in (19), for the robust (continuous lines) and conventional (dashed line) PI controllers. $\mathscr{H}_{\infty}$ guaranteed costs given, respectively, by $1.0517 \mathrm{~dB}$ and $5.1469 \mathrm{~dB}$.

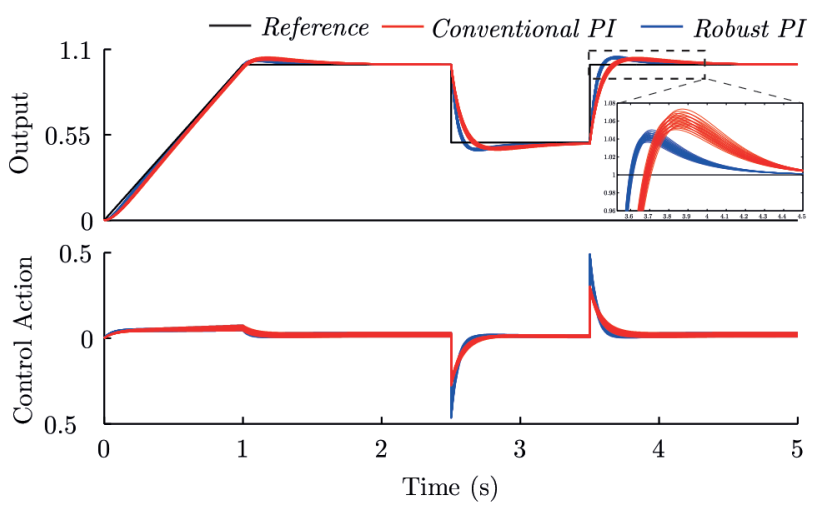

Fig. 11. Responses to a reference with a startup in ramp and with variations of setpoints, for the robust and conventional PIs.

in Figure 11. This figure shows a test with a reference of speed with a start up in ramp and with variations of setpoint. It is clear the good tracking of the reference and the good recovering at the setpoint variations with both controllers, with faster responses for the robust PI controller.

To obtain the experimental results, the platform used here was based on a commercial PMSM with nominal parameters in Table I. The DSP TI TMS320F28335 is used to implement the digital control law. The three-phase voltage source inverter (VSI) is based on IGBT switches. Hall effect sensors are employed, for voltage and current measurements. An absolute encoder TRD-NA256NWD provides the actual rotor position. A geometric PWM modulation is adopted. The switching frequency used was $10 \mathrm{kHz}$, the sampling period is $100 \mu \mathrm{s}$, and the PI controllers are discretized using Tustin method.

Figure 12 shows the experimental platform, where an induction machine (IM), is coupled to the axis of the PMSM. The electrical load shown in Figure 12 is connected to the IM to produce a mechanical load disturbance of approximately $25 \mathrm{Nm}$ for the PMSM.

Figure 13 shows the experimental results with the robust PI controller (22), for a test of tracking of reference similar to the simulation test in Figure 11. Note the good tracking of the reference of speed during the startup and after the variations of setpoints, with the robust PI controller. Currents $i_{q}$ and $i_{d}$

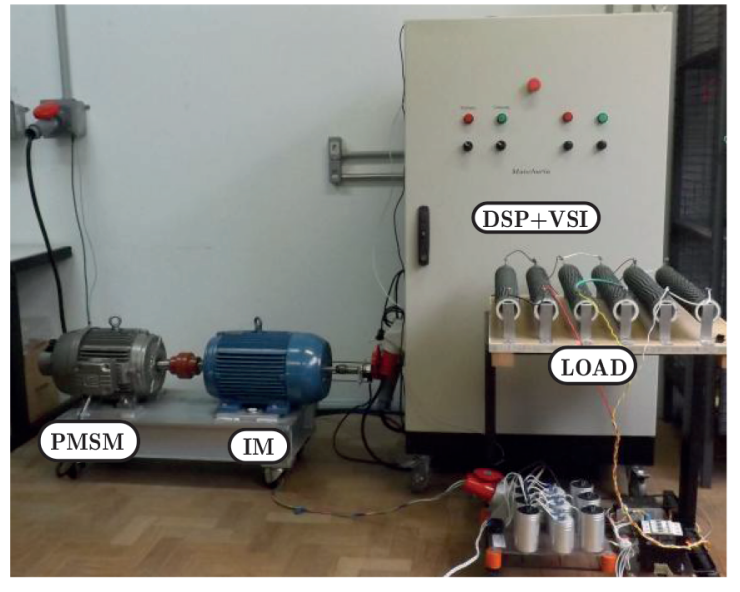

Fig. 12. Photograph of the prototype.

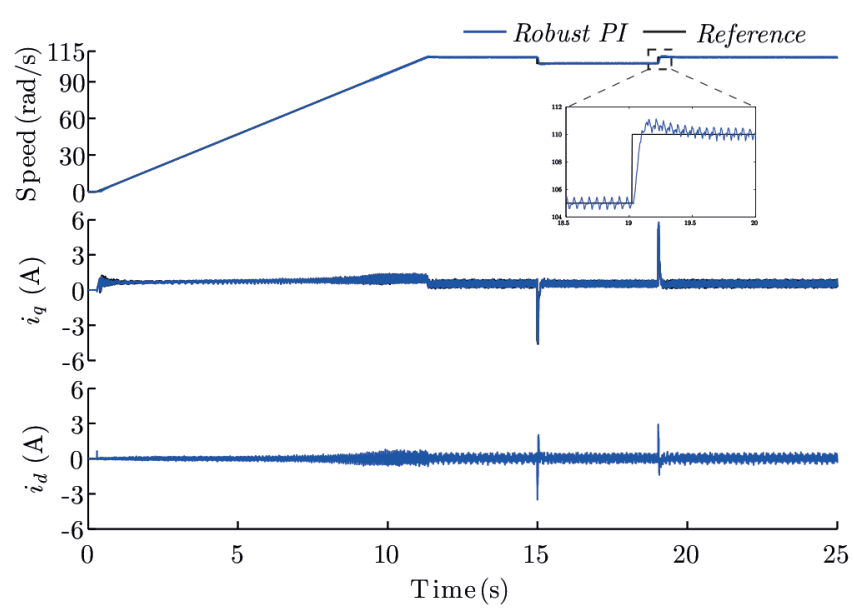

Fig. 13. Experimental results for speed reference tracking with the robust PI controller.

are shown in Figure 13, being $i_{q}$, actually, the control signal, showing the same pattern of the simulated control signal in Figure 11.

Repeating the tests of reference tracking of Figure 13, for a comparison among the conventional and robust PI controllers, one has the experimental results in Figure 14. These experimental results confirm a better dynamic performance with the robust PI controller with respect to the conventional PI controller.
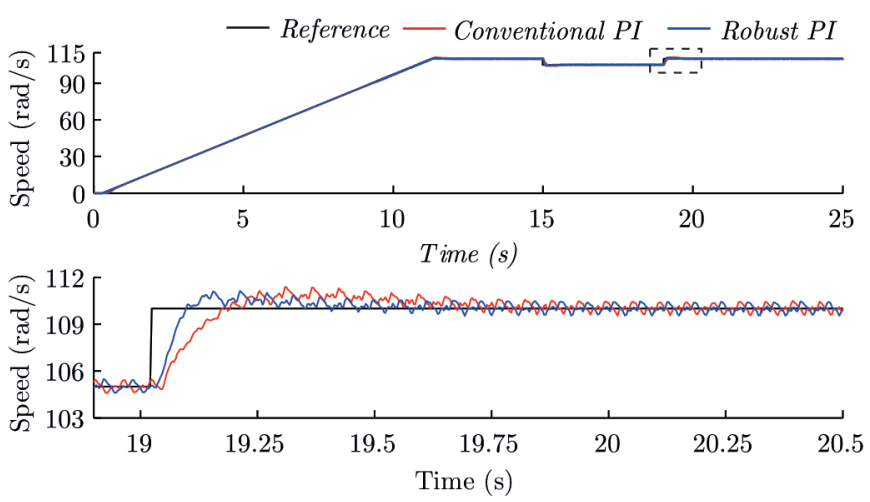

Fig. 14. Experimental results for speed reference tracking with the conventional and the robust PI controllers (top) and detail after the sudden increase of the reference (bottom). 
The absolute value of the errors in Figure 14 (bottom) are shown in Figure 15. It is clear from this figure that the overall performance with the robust PI controller is superior than that with the conventional PI. This is corroborated by the integral of the absolute errors of these waveforms, which results in 151.9404 for the robust PI controller and 240.5828 for the conventional PI controller.

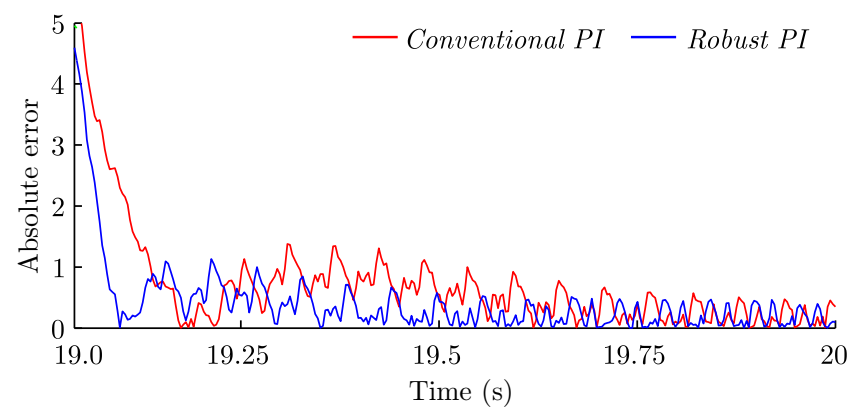

Fig. 15. Absolute values of the errors from Figure 14, with the robust and the conventional PI controllers.

In Figure 16, one has the experimental results for rejection of a step load disturbance imposed by means of the IM in Figure 12. It is possible to notice the better rejection of disturbances provide by the robust PI, when compared to the conventional PI, with fast transient recovers. This changing of the load conditions show the performance of the proposed controller, and illustrates its robustness.

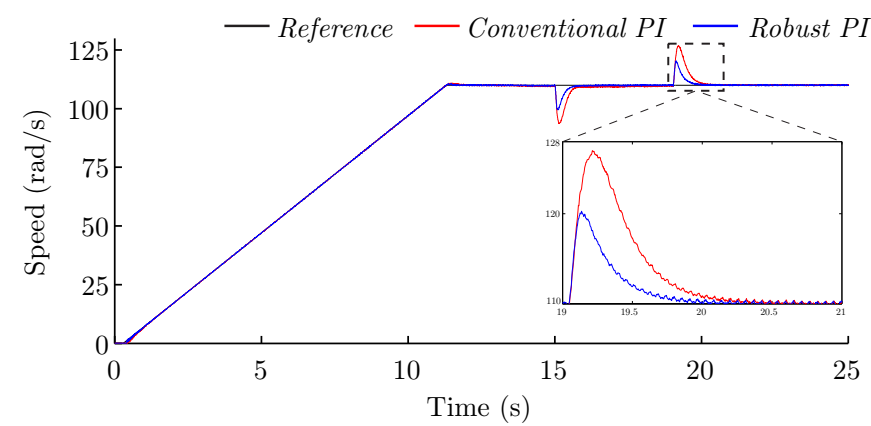

Fig. 16. Experimental results for the rejection of a load disturbance for the robust and for the conventional PIs.

Finally, Figure 17 illustrates the responses to a step in the reference of speed, with simulation results for the robust PI controller for a grid on $a$ and $b$, and the respective experimental response. One can see by the good correspondence of the simulation and experimental results in Figure 17 that the linearized model used here suitably reproduces the average behavior of the physical system. The ripple observed in the experimental variable in Figure 17 does not appear in the simulation, since the plant linearized models are of first order. Although simple, these plant models are sufficient for the design of the robust controllers shown here.

\section{CONCLUSIONS AND PERSPECTIVES}

This paper presented the design of robust PIs for speed control of PMSMs. A polytopic model is used to include the parameter uncertainties of the motor. A design based

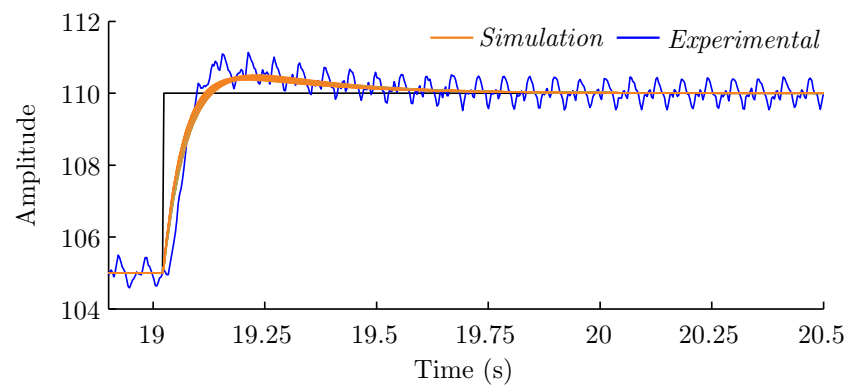

Fig. 17. Comparison of the simulations of the linearized model with the experimental result. Reference signal in black, model simulations in orange, and experimental result in blue, all for the robust PI controller.

on LMIs provides the gains of robust PI controllers in a fast numerical solution. A procedure based on the choice of the parameters of the LMIs is given to obtain time responses with prescribed upper bounds for overshoots, settling times and control signals. The simulation and the experimental results indicate the superior performance of the robust PI with respect to a PI designed only for the nominal parameters, considering reference tracking and disturbance rejection. The existence of a Lyapunov function, provided by the LMIs, proves the robust stability under arbitrary variations of the parameters of the motor. The proposed framework is applicable to the design of robust PIs for the wide class of first order plants in (7), and will be evaluated in sensorless control for PMSM applications in future works

\section{ACKNOWLEDGEMENTS}

To the Brazilian agencies CAPES and CNPq (Project 306197/2015-4)

\section{REFERENCES}

[1] R. Krishnan, Electric motor drives: modeling, analysis, and control, Prentice Hall, 2001.

[2] A. M. EL-Refaie, "Fractional-Slot ConcentratedWindings Synchronous Permanent Magnet Machines: Opportunities and Challenges", IEEE Transactions on Industrial Electronics, vol. 57, no. 1, pp. 107-121, Jan 2010.

[3] A. Emadi, Y. J. Lee, K. Rajashekara, "Power Electronics and Motor Drives in Electric, Hybrid Electric, and Plug-In Hybrid Electric Vehicles", IEEE Transactions on Industrial Electronics, vol. 55, no. 6 , pp. 2237-2245, June 2008.

[4] B. Hafez, A. S. Abdel-Khalik, A. M. Massoud, S. Ahmed, R. D. Lorenz, "Single-Sensor-Based Three-Phase Permanent-Magnet Synchronous Motor Drive System With Luenberger Observers for Motor Line Current Reconstruction", IEEE Transactions on Industry Applications, vol. 50, no. 4, pp. 2602-2613, July 2014.

[5] R. Ni, D. Xu, G. Wang, L. Ding, G. Zhang, L. Qu, "Maximum Efficiency Per Ampere Control of Permanent-Magnet Synchronous Machines", IEEE Transactions on Industrial Electronics, vol. 62, no. 4, pp. 2135-2143, April 2015. 
[6] C. Xia, B. Ji, Y. Yan, "Smooth Speed Control for Low-Speed High-Torque Permanent-Magnet Synchronous Motor Using Proportional-IntegralResonant Controller", IEEE Transactions on Industrial Electronics, vol. 62, no. 4, pp. 2123-2134, April 2015.

[7] J. Jang, M. Humza, B. Kim, "Design of a VariableFlux Permanent-Magnet Synchronous Motor for Adjustable-Speed Operation", IEEE Transactions on Industry Applications, vol. 52, no. 4, pp. 2996-3004, July 2016.

[8] S. Yamamoto, H. Hirahara, A. Tanaka, T. Ara, K. Matsuse, "Universal Sensorless Vector Control of Induction and Permanent-Magnet Synchronous Motors Considering Equivalent Iron Loss Resistance", IEEE Transactions on Industry Applications, vol. 51, no. 2, pp. 1259-1267, March 2015.

[9] T. Bernardes, V. F. Montagner, H. A. Grundling, H. Pinheiro, "Discrete-Time Sliding Mode Observer for Sensorless Vector Control of Permanent Magnet Synchronous Machine", IEEE Transactions on Industrial Electronics, vol. 61, no. 4, pp. 1679-1691, April 2014.

[10] G. H. Negri, F. G. Nazário, J. de Oliveira, A. Nied, "Back-emf based rotor position estimation for low cost PMSM drive using fully connected cascade artificial neural networks", Revista Eletrônica de Potência, vol. 23, no. 1, pp. 69 - 77, March 2018.

[11] E. de M. Fernandes, A. C. Oliveira, A. M. N. Lima, C. B. Jacobina, "Estimação de posição rotórica de motor PMSM com minimização da distorção da tensão de alta frequência", Revista Eletrônica de Potência, vol. 17 , no. 1, pp. $447-455$, February 2012.

[12] S. Li, Z. Liu, "Adaptive Speed Control for PermanentMagnet Synchronous Motor System With Variations of Load Inertia", IEEE Transactions on Industrial Electronics, vol. 56, no. 8, pp. 3050-3059, Aug 2009.

[13] J. W. Jung, V. Q. Leu, T. D. Do, E. K. Kim, H. H. Choi, "Adaptive PID Speed Control Design for Permanent Magnet Synchronous Motor Drives", IEEE Transactions on Power Electronics, vol. 30, no. 2, pp. 900-908, Feb 2015.

[14] X. Zhang, L. Sun, K. Zhao, L. Sun, "Nonlinear Speed Control for PMSM System Using Sliding-Mode Control and Disturbance Compensation Techniques", IEEE Transactions on Power Electronics, vol. 28, no. 3, pp. 1358-1365, March 2013.

[15] A. G. Bartsch, G. H. Negri, C. R. Scalabrin, M. S. M. Cavalca, A. Nied, J. de Oliveira, "Predictive control approach for permanent magnet synchronous motor drive", Revista Eletrônica de Potência, vol. 20, no. 4, pp. 395 - 403, November 2015.

[16] V. Q. Leu, H. H. Choi, J. W. Jung, "Fuzzy Sliding Mode Speed Controller for PM Synchronous Motors With a Load Torque Observer", IEEE Transactions on Power Electronics, vol. 27, no. 3, pp. 1530-1539, March 2012.

[17] S. Boyd, L. El Ghaoui, E. Feron, V. Balakrishnan, Linear Matrix Inequalities in System and Control Theory, SIAM Studies in Applied Mathematics, Philadelphia, PA, 1994.
[18] H. H. Choi, N. T. T. Vu, J. W. Jung, "Design and Implementation of a Takagi-Sugeno Fuzzy Speed Regulator for a Permanent Magnet Synchronous Motor", IEEE Transactions on Industrial Electronics, vol. 59, no. 8, pp. 3069-3077, Aug 2012.

[19] R. C. García, J. O. P. Pinto, E. A. Batista, L. Galotto, "Design of a MIMO IMC-TS fuzzy speed controller for PMSM", in Proc. of Brazilian Power Electronics Conference (COBEP), pp. 1-6, 2017.

[20] K. Astrom, T. Hagglund, PID Controllers, International Society for Measurement and Control, 1995.

[21] J. Dannehl, F. W. Fuchs, S. Hansen, P. B. Thogersen, "Investigation of Active Damping Approaches for PI-Based Current Control of Grid-Connected Pulse Width Modulation Converters With LCL Filters", IEEE Transactions on Industry Applications, vol. 46, no. 4, pp. 1509-1517, July 2010.

[22] R. Kadri, J. P. Gaubert, G. Champenois, "An Improved Maximum Power Point Tracking for Photovoltaic Grid-Connected Inverter Based on Voltage-Oriented Control", IEEE Transactions on Industrial Electronics, vol. 58, no. 1, pp. 66-75, Jan 2011.

[23] D. R. Espinoza-Trejo, E. Barcenas-Barcenas, D. U. Campos-Delgado, C. H. D. Angelo, "VoltageOriented Input-Output Linearization Controller as Maximum Power Point Tracking Technique for Photovoltaic Systems", IEEE Transactions on Industrial Electronics, vol. 62, no. 6, pp. 3499-3507, June 2015.

[24] D. G. Holmes, B. P. McGrath, S. G. Parker, "Current Regulation Strategies for Vector-Controlled Induction Motor Drives", IEEE Transactions on Industrial Electronics, vol. 59, no. 10, pp. 3680-3689, Oct 2012.

[25] E. de M. Fernandes, D. R. Huller, A. C. Oliveira, M. B. de R. Corrêa, W. R. N. Santos, "Simulador em tempo real para motor síncrono como íma permanente baseado em dispositivos lógicos programáveis", Revista Eletrônica de Potência, vol. 20, no. 3, pp. 244 - 253, August 2015.

[26] M. Ge, M.-S. Chiu, Q.-G. Wang, "Robust PID controller design via LMI approach", Journal of Process Control, vol. 12, no. 1, pp. 3 - 13, January 2002.

[27] H. Zhang, Y. Shi, A. Mehr, "Robust Static Output Feedback Control and Remote PID Design for Networked Motor Systems", IEEE Transactions on Industrial Electronics, vol. 58, no. 12, pp. $5396-5405$, December 2011.

[28] A. Guagnano, G. Rizzello, F. Cupertino, D. Naso, "Robust Control of High-Speed Synchronous Reluctance Machines", IEEE Transactions on Industry Applications, vol. 52, no. 5, pp. 3990-4000, Sept 2016.

[29] X. Sun, Y. Yi, W. Zheng, T. Zhang, "Robust PI speed tracking control for PMSM system based on convex optimization algorithm", in Proc. of the 33rd Chinese Control Conference, pp. 4294-4299, 2014. 
[30] P. Krause, O. Wasynczuk, S. Sudhoff, Analysis of Electric Machinery and Drive Systems, second ed., Wiley-IEEE Press, United States of America, 2002.

[31] K.-H. Kim, M.-J. Youn, "A nonlinear speed control for a PM synchronous motor using a simple disturbance estimation technique", IEEE Transactions on Industrial Electronics, vol. 49, no. 3, pp. 524-535, Jun 2002.

[32] R. Krishnan, Permanent Magnet Synchronous and Brushless DC Motor Drives, Mechanical Engineering (Marcel Dekker), 1 ed., CRC Press, 2009.

[33] M. Chilali, P. Gahinet, P. Apkarian, "Robust pole placement in LMI regions", IEEE Transactions on Automatic Control, vol. 44, no. 12, pp. 2257-2270, December 1999.

\section{BIOGRAPHIES}

Gustavo Guilherme Koch was born in Ijuí, RS, Brazil, in 1988. He received the B.Sc. and M.Sc. degrees in electrical engineering in 2013 and 2015, respectively, from the Federal University of Santa Maria, Santa Maria, Brazil, where he is currently working toward the Ph.D. degree. His research interests include robust control, and control theory applications.

Thieli Smidt Gabbi was born in Santa Maria, RS, Brazil, in 1989. She received the B.Sc. and M.Sc. degrees in electrical engineering in 2013 and 2015, respectively, from the Federal University of Santa Maria, Santa Maria, Brazil, where she is currently working toward the Ph.D. degree. Her research interests include control systems and eletrical machine drives.

Rodrigo Padilha Vieira was born in Cruz Alta, Brazil. He received the B.S. degree in electrical engineering from the Universidade Regional do Noroeste do Estado do Rio Grande do Sul (UNIJUI), Ijuí, Brazil, in 2007, and the M.S. and Dr. Eng. degrees in electrical engineering from the Federal University of Santa Maria (UFSM), Santa Maria, Brazil, in 2008 and 2012, respectively. From 2010 to 2014, he was with the Federal University of Pampa, Alegrete, Brazil. Since 2014, he has been with the UFSM, where he is currently an Adjunct Professor. His research interests include electrical machine drives, sliding mode control, and digital control techniques of static converters.
Humberto Pinheiro was born in Santa Maria, Brazil, in 1960. He received the B.Sc. degree from the Federal University of Santa Maria, Santa Maria, Brazil, in 1983, the M.Eng. degree from the Federal University of Santa Catarina, Florianópolis, Brazil, in 1987, and the Ph.D. degree from Concordia University, Montreal, QC, Canada, in 1999. From 1987 to 1990, he was a Research Engineer with a Brazilian UPS company and then joined the Pontifícia Universidade Católica do Rio Grande do Sul, Brazil, where he lectured on power electronics. Since 1991, he has been with the Federal University of Santa Maria. His current research interests include grid-connected three-phase converters, wind energy conversion systems, and control applied to power electronics.

Thiago Araújo Bernardes was born in Natal, RN, Brazil, in 1983. He received the B.Sc. degree in electrical engineering from the Federal University of Ceara in2007, and the M.Sc. and D.Sc. degrees in electrical engineering from Federal University of Santa Maria, Santa Maria, Brazil, in 2009 and 2013, respectively. He is effective professor at the Federal Institute of Ceará - Sobral. His research interests include: sliding mode control, control applied to power electronics systems, wind energy conversion systems, control systems connected to the grid and energy efficiency.

Ricardo Coração de Leão Fontoura de Oliveira was born in Assis Chateaubriand, Parana, Brazil, in 1978. He received the B.Sc. degree in computer engineering from the Pontifical Catholic University of Parana in 2001 and the M.Sc. and $\mathrm{Ph} . \mathrm{D}$. degrees in electrical engineering from the University of Campinas (UNICAMP), Campinas, SP, Brazil, in 2003 and 2006, respectively. He is currently a Professor with the School of Electrical and Computer Engineering, UNICAMP. His research interests include the development of numerical tools for stability analysis and the control design of uncertain linear and fuzzy systems.

Vinícius Foletto Montagner received the Master's degree in electrical engineering from the Federal University of Santa Maria, Santa Maria, Brazil, in 2000, and the Ph.D. degree in electrical engineering from the University of Campinas, Campinas, Brazil, in 2005. He is currently a Professor in the Federal University of Santa Maria, where he works with the Power Electronics and Control Research Group (GEPOC). His research interests include robust stability and control applied to power electronics. 